\title{
Impact of $0.1 \%$ sodium hyaluronate and $0.2 \%$ sodium hyaluronate artificial tears on postoperative discomfort following cataract extraction surgery: a comparative study
}

Panagiota Ntonti ${ }^{1,2^{*}}$ (D), Eirini-Kanella Panagiotopoulou' ${ }^{1}$ Georgios Karastatiras ${ }^{3}$, Nektarios Breyannis ${ }^{4}$, Sevasti Tsironi ${ }^{2}$ and Georgios Labiris ${ }^{1}$

\begin{abstract}
Background: Recent artificial tear preparations have provided $0.2 \%$ concentration of sodium hyaluronate. However, no published data exist on their potential superiority against $0.1 \%$ in alleviating dry-eye-disease symptoms in cataract extraction surgery.

Methods: A total of 180 patients that underwent cataract extraction surgery were randomly divided into 2 groups according to their postoperative regime: Study group (SG) received fixed combination of tobramycin and dexamethasone (FCTD) quid for 3 weeks, and additionally $0.2 \%$ sodium hyaluronate provided in the COMOD ${ }^{\oplus}$ device quid for 6 weeks. Control group (CG) received fixed combination of tobramycin and dexamethasone (FCTD) quid for 3 weeks, and additionally $0.1 \%$ sodium hyaluronate provided in the COMOD ${ }^{\circledR}$ device quid for 6 weeks. The following indexes were evaluated at 3 postoperative checkpoints: 1) Surface discomfort index (SDI) which was derived by four direct 10-scale Likert-type questions that were addressed to the patient and pertained to: a) foreign body sensation (FBS), b) blinking discomfort (BD), c) stinging sensation (SS), d) tearing sensation (TS), 2) Tear breakup time (TBUT), 3) Schirmer's test, 4) Central corneal thickness (CCT), and 4) Central Corneal Sensitivity (CCS).
\end{abstract}

Results: Both groups showed reduced CCS values at all postoperative examination points; however, SG participants had significantly better CCS (all $p<0.05)$. SG had better TBUT than CG at the 3rd ( $p=0.03$ ) and 6th examination points $(p=0.04)$. Moreover, SG had better SDI scores at the 3rd $(\mathrm{SDI}=9.26 \pm 0.55)$ and 6 th weeks $(\mathrm{SDI}=9.47 \pm 0.48)$ vs. CG participants ( $p=0.03$ and $p<0.01$, respectively).

Conclusion: The increased $0.2 \%$ sodium hyaluronate concentration in the artificial tears provided in the $\mathrm{COMOD}^{\odot}$ device seems to address dry-eye-disease symptoms better in patients who underwent phacoemulsification surgery than the $0.1 \%$ concentration.

Trial registration: ClinicalTrials.gov Identifier: NCT03705949 Oct 15, 2018, retrospectively registered.

Keywords: Cataract, Postoperative regime, Artificial tears, Surface discomfort index, Hylocomod, Hylogel, Sodium hyaluronate

\footnotetext{
*Correspondence: giotado@hotmail.com

1 Department of Ophthalmology, University Hospital of Alexandroupolis,

68100 Dragana, Alexandroupolis, Greece

${ }^{2}$ Department of Ophthalmology, Papanikolaou General Hospital, Thessaloniki,

Greece

Full list of author information is available at the end of the article
}

(c) The Author(s). 2019 Open Access This article is distributed under the terms of the Creative Commons Attribution 4.0 International License (http://creativecommons.org/licenses/by/4.0/), which permits unrestricted use, distribution, and reproduction in any medium, provided you give appropriate credit to the original author(s) and the source, provide a link to the Creative Commons license, and indicate if changes were made. The Creative Commons Public Domain Dedication waiver (http://creativecommons.org/publicdomain/zero/1.0/) applies to the data made available in this article, unless otherwise stated. 


\section{Background}

Cataract is one of the most prevalent medical conditions, being responsible for about 33\% of visual incapacity worldwide and $51 \%$ of blindness [1-3]. No reliable conventional treatment means (i.e., drops) exist for cataract, therefore, the treatment of choice is exclusively surgical. Cataract extraction surgery is a minimally invasive technique, usually performed in an outpatient basis [4]. In the vast majority of cases, patients experience a short, uneventful recovery period [5]. Following an uncomplicated operation, the patient has to be administered drops that minimize surgical-induced inflammation and facilitate visual recovery. Regardless of the specific active ingredients, the postoperative regime primarily aims to prevent macular edema, corneal edema, and endophthalmitis [4, 6, 7].

Further to the aforementioned rare but potentially sight-threatening complications, a significant percentage of patients experience symptoms compatible to ocular surface disease (OSD) [8-10]. Among the most frequent OSD symptoms are the foreign body sensation, itching and ocular pain $[11,12]$. The pathomechanism of OSD in cataract surgery is associated with both nerve transection during corneal incisions and the local inflammation that contribute to tear film instability $[13,14]$.

A recent publication from our group indicated the necessity of adding artificial tears to the standard postoperative regime to prevent OSD [15]. According to our report, as well as other similar publications, patients who additionally receive artificial tears in the postoperative regime have significant better scores in break-up-time and significantly less subjective discomfort $[15,16]$.

Among the prevalent artificial tear medications that have been suggested to alleviate OSD symptomatology in post cataract patients is the $0.1 \%$ sodium hyaluronate provided in the continuous monodose system COMOD ${ }^{\circ}$ (Hylocomod, Farmex, Greece). The COMOD device is an integral airless application system, which enables delivery of multiple sterile doses of a liquid medicinal product. However, $0.2 \%$ sodium hyaluronate (Hylogel, Farmex, Greece) that is provided in the exact same COMOD system has been introduced to the market that promises enhanced efficacy due to the double sodium hyaluronate concentration [15]. To our knowledge, no published reports have compared the necessity of $0.2 \%$ sodium hyaluronate over $0.1 \%$ in cataract extraction surgery. Within this context, this study objective was to compare the impact of these artificial tear preparations on postoperative discomfort following cataract extraction surgery.

\section{Material/methods}

\section{Setting}

This was a prospective, multicentered, randomized trial. Study protocol adhered to the tenets of the Declaration of Helsinki and written informed consent was obtained from all participants. The institutional review board of the Democritus University of Thrace approved the protocol and the study was conducted at the University Hospital of Alexandroupolis, Naval Hospital in Athens, Papanikolaou General Hospital in Thessaloniki, and Athinaiki General Clinic in Athens, Greece between September 2017 and September 2018.

\section{Participants}

Participants were recruited from the Cataract Service of the aforementioned hospitals in a consecutive-if-eligible basis. Eligibility criteria included diagnosis of senile cataract with stage 2 or 3 nuclear opalescence according to the Lens Opacities Classification System III (LOCS-3) grading scale. Exclusion criteria for all study groups included: diagnosis or evidence of dry-eye-disease (DED), IOP-lowering medications, former incisional surgery, former diagnosis of corneal disease, diabetes, autoimmune or mental diseases. By means of a custom computer randomization program, all participants were randomly assigned to two study groups according to the postoperative regime that was prescribed: a) Study group (SG) received fixed combination of tobramycin and dexamethasone (FCTD), (Tobradex, Alcon, Greece) quid for 3 weeks and $0.2 \%$ sodium hyaluronate (Hylogel) quid for 6 weeks, and b) Control Group (CG) received Tobradex quid for 3 weeks and $0.1 \%$ sodium hyaluronate (Hylocomod) quid for 6 weeks.

\section{Surgical technique}

Despite the fact that four different surgeons performed the operations in the different centers, a consistent surgical methodology was followed to minimize the impact of surgical technique in the study outcomes. For example, all surgeons performed a $2.2 \mathrm{~mm}$, superior-temporal or superior-nasal (eleven o'clock), self-sealing, clear-cornea incision, and two contralateral stabs. They used the same viscoelastic devices and intraocular lenses, exactly as described in a former report from our group [15].

\section{Data collection}

The following parameters were comparatively evaluated one, three and six weeks postoperatively: 1) Surface discomfort index (SDI), 2) Schirmer test, 3) Tear break-up time (TBUT), 4) Central corneal thickness (CCT) using anterior segment optical coherence tomography, and 5) Central Corneal Sensitivity (CCS) using the Cochet-Bonnet aesthesiometer. SDI is a novel corneal discomfort parameter that evaluates: a) foreign body sensation (FBS), b) blinking discomfort (BD), c) stinging sensation (SS), and d) tearing sensation (TS). For detailed presentation of SDI and its validation process please refer to a former publication from our group [15]. 
Table 1 Preoperative data for all participants

\begin{tabular}{lcccccc}
\hline Group & No. & & Age & & & BSCVA \\
& & Years & SD & & LogMAR & SD \\
\hline CG & 90 & 72.9 & 7.8 & & 0.92 & 0.07 \\
SG & 90 & 72.4 & 8.7 & & 0.80 & 0.05 \\
$p$-value & & 0.69 & & 0.48 & \\
\hline
\end{tabular}

CG control group, SG study group, BSCVA best-spectacles corrected visual acuity, SD standard deviation

\section{Statistical analysis}

An a priori power analysis was performed. For an effect size of 0.35 of the SDI, 72 participants would be required in each group for the study to have a power of 0.8 at the significance level of 0.05 . The normality of measured data was evaluated by the Kolmogorov-Smirnov test. Normal distribution data were assessed by Student's t-test. Non-parametric data were assessed with MannWhitney $\mathrm{U}$ test. Values at the $p<0.05$ were considered statistically significant. All statistical analyses were performed with the Medcalc version 9.6.2.0 (Medcalc Software, Mariakerke, Belgium).

\section{Results}

One hundred eighty patients (82 men and 98 women, mean age $72.7 \pm 8.28$ years) were recruited and randomly assigned study (90 participants) or control (90 participants) groups. Detailed demographic and clinical parameters are presented in Tables 1 and 2. Non-significant differences were detected with respect to age $(p=0.69)$ and BSCVA $(p=0.48)$ among the groups. No parameter demonstrated significant differences between the two groups preoperatively.

Table 2 Group comparisons preoperatively

\begin{tabular}{|c|c|c|c|}
\hline \multirow[b]{2}{*}{ Parameter (mean \pm SD) } & \multicolumn{3}{|l|}{ Preoperative } \\
\hline & $\mathrm{CG}$ & SG & $p$-value \\
\hline $\mathrm{CCT}(\mu \mathrm{m})$ & $537 \pm 36$ & $544 \pm 34$ & 0.22 \\
\hline $\operatorname{CCS}(\mathrm{cm})$ & $5.76 \pm 1.39$ & $5.74 \pm 1.34$ & 0.35 \\
\hline TBUT (secs) & $11.51 \pm 7.08$ & $11.92 \pm 6.92$ & 0.69 \\
\hline Schirmer (mm) & $11.64 \pm 3.43$ & $11.93 \pm 3.60$ & 0.58 \\
\hline FBS & NA & NA & NA \\
\hline $\mathrm{BD}$ & NA & NA & NA \\
\hline SS & NA & NA & NA \\
\hline TS & NA & NA & NA \\
\hline SDI & NA & NA & NA \\
\hline
\end{tabular}

Table 3 Group comparisons (1st postoperative week)

\begin{tabular}{llll}
\hline & 1 st week & & \\
\cline { 2 - 4 } Parameter (mean \pm SD) & CG & SG & $p$-value \\
\hline CCT $(\mu \mathrm{m})$ & $567 \pm 43 b$ & $570 \pm 44 b$ & 0.66 \\
CCS $(\mathrm{cm})$ & $3.34 \pm 1.21 b$ & $3.98 \pm 1.15 b$ & $0.01^{*}$ \\
TBUT $($ secs $)$ & $11.00 \pm 6.76$ & $12.04 \pm 7.82$ & 0.34 \\
Schirmer $(\mathrm{mm})$ & $11.93 \pm 3.49$ & $11.47 \pm 3.66$ & 0.32 \\
FBS & $8.98 \pm 0.89$ & $9.01 \pm 1.08$ & 0.82 \\
BD & $8.92 \pm 1.04$ & $9.03 \pm 0.84$ & 0.43 \\
SS & $8.94 \pm 1.03$ & $9.20 \pm 0.93$ & 0.08 \\
TS & $8.90 \pm 0.85$ & $8.98 \pm 0.94$ & 0.56 \\
SDI & $8.93 \pm 0.71$ & $9.06 \pm 0.72$ & 0.25 \\
\hline
\end{tabular}

CG control group, SG study group, CCT central corneal thickness, CCS central corneal sensitivity, TBUT tear break up time, FBS foreign body sensation, $B D$ blinking discomfort, SS stinging sensation, TS tearing sensation, SDI surface discomfort index, $S D$ standard deviation $b$ indicates significant difference with preoperative values ${ }^{*} p<0.05$

All postoperative comparisons are presented in Tables 3, 4 and 5 . While $0.1 \%$ sodium hyaluronate participants demonstrated significantly increased CCT values at all examination points in comparison to the preoperative values (all $p<0.05$ ), $0.2 \%$ sodium hyaluronate participants regained CCT preoperative values at the last examination point (preoperative: $544 \pm 34 \mu \mathrm{m}$, 6th week: $542 \pm 35 \mu \mathrm{m}, p=0.08$; Fig. 1 ).

With respect to CCS, participants in both groups demonstrated reduced corneal sensitivity at all postoperative examination points. However, despite the overall reduction in CCS, $0.2 \%$ sodium hyaluronate

Table 4 Group comparisons (3rd week postoperatively)

\begin{tabular}{llll}
\hline \multirow{2}{*}{ Parameter (mean \pm SD) } & CG & SG & $p$-value \\
\cline { 2 - 4 } CCT $(\mu \mathrm{m})$ & $549 \pm 35 b$ & $553 \pm 39 b$ & 0.53 \\
CCS $(\mathrm{cm})$ & $4.02 \pm 1.01 b$ & $4.54 \pm 1.22 b$ & $0.04^{*}$ \\
TBUT $(\mathrm{secs})$ & $12.46 \pm 8.07 b$ & $14.68 \pm 8.73 b$ & $0.03^{*}$ \\
Schirmer $(\mathrm{mm})$ & $12.57 \pm 3.52 b$ & $12.76 \pm 3.42 b$ & 0.72 \\
FBS & $9.08 \pm 0.82$ & $9.26 \pm 0.92$ & 0.17 \\
BD & $9.10 \pm 0.96$ & $9.26 \pm 0.63$ & 0.20 \\
SS & $9.12 \pm 0.89$ & $9.40 \pm 0.73$ & $0.02^{*}$ \\
TS & $9.02 \pm 0.72$ & $9.14 \pm 1.11$ & 0.38 \\
SDI & $9.08 \pm 0.60$ & $9.26 \pm 0.55$ & $0.03^{*}$ \\
\hline CG control & &
\end{tabular}

CG control group, SG study group, CCT central corneal thickness, CCS central corneal sensitivity, TBUT tear break up time, FBS foreign body sensation, $B D$ blinking discomfort, SS stinging sensation, $T$ tearing sensation, $S D I$ surface discomfort index, $S D$ standard deviation

$b$ indicates significant difference with preoperative values ${ }^{*} p<0.05$ 
Table 5 Group comparisons (6th week postoperatively)

\begin{tabular}{llll}
\hline & \multicolumn{3}{l}{6 th week } \\
\cline { 2 - 4 } Parameter (mean \pm SD) & CG & SG & $p$-value \\
\hline CCT $(\mu \mathrm{m})$ & $545 \pm 32 b$ & $542 \pm 35$ & 0.87 \\
CCS $(\mathrm{cm})$ & $4.02 \pm 1.04 b$ & $4.56 \pm 1.16 b$ & $0.01^{*}$ \\
TBUT $(\mathrm{secs})$ & $12.52 \pm 8.74 b$ & $14.62 \pm 9.73 b$ & $0.04^{*}$ \\
Schirmer $(\mathrm{mm})$ & $13.54 \pm 3.90 b$ & $14.21 \pm 3.61 b$ & 0.24 \\
FBS & $9.12 \pm 0.67$ & $9.46 \pm 0.85$ & $0.04^{*}$ \\
BD & $9.34 \pm 0.75$ & $9.50 \pm 0.57$ & 0.12 \\
SS & $9.14 \pm 0.89$ & $9.57 \pm 0.69$ & $<0.01$ \\
TS & $9.18 \pm 0.74$ & $9.36 \pm 0.69$ & 0.10 \\
SDI & $9.27 \pm 0.52$ & $9.47 \pm 0.48$ & $<0.01$ \\
\hline
\end{tabular}

CG control group, SG study group, CCT central corneal thickness, CCS central corneal sensitivity, TBUT tear break up time, FBS foreign body sensation, $B D$ blinking discomfort, SS stinging sensation, TS tearing sensation, SDI surface discomfort index, $S D$ standard deviation

$b$ indicates significant difference with preoperative values ${ }^{*} p<0.05$

members presented significantly better corneal sensitivity vs. control (1st week: SG: $3.98 \pm 1.15$, CG: $3.34 \pm$ 1.21, $p=0.01$, 3rd week: SG: $4.54 \pm 1.22$, CG: $4.02 \pm$ $1.01, p=0.04$, 6th week: SG: $4.56 \pm 1.16$, CG: $4.02 \pm$ 1.04, $\mathrm{p}=0.01$; Fig. 2).

Significant differences among groups' participants were detected in the TBUT parameter, as well. Both groups demonstrated non-significant improvement in TBUT at the first postoperative timepoint (both $p>$ $0.05)$. At the 3rd and 6th weeks both 0.1 and $0.2 \%$ sodium hyaluronate participants presented significant improvement in comparison to their preoperative values; however, TBUT significantly improved in $0.2 \%$ participants in comparison to the $0.1 \%$ group (3rd week: SG: $14.68 \pm 8.73 \mathrm{~s}, \mathrm{CG}: 12.46 \pm 8.07 \mathrm{~s}, p=0.03$, 6th week: SG: $14.68 \pm 8.73$ s, CG: $12.52 \pm 8.74 \mathrm{~s}, p=$ 0.04; Fig. 3).

On the other hand, both groups presented similar results in Schirmer's test. Significant increase in the Schirmer test was detected at the 3rd and 6th weeks. Non-significant differences could be detected between groups at all timepoints (Fig. 4).

Regarding the subjective discomfort as expressed by our study participants, $0.2 \%$ sodium hyaluronate participants demonstrated significant better SDI scores at the 3rd (SG: $9.26 \pm 0.55$, CG: $9.08 \pm 0.60, p=0.03$ ) and 6th (SG: $9.47 \pm 0.48$, CG: $9.27 \pm 0.52, p<0.01$ ) weeks (Fig. 5). The overall improved score in the SDI parameter was primarily attributed to the significant better score in the Stinging Sensation index at the 3rd $(p=0.02)$ and 6th weeks $(p<0.01$, Fig. 6) and additionally in the Foreign Body Sensation Index at the 6th week ( $p=0.04$, Fig. 7).

\section{Discussion}

Phacoemulsification is considered the most prevalent surgical procedure in ophthalmology both in developed and in developing countries $[17,18]$. Despite the advances in cataract-extraction technology, this common surgical technique has been associated with a series of intraoperative and postoperative adverse-effects and complications. Transient corneal edema and reduced corneal sensitivity are two of the mild adverse-effects. Among the more severe ones is the permanent corneal decompensation due to endothelial cell damage. Nevertheless, according to the majority of recently published reports, cataract surgery delivers favorable outcomes in

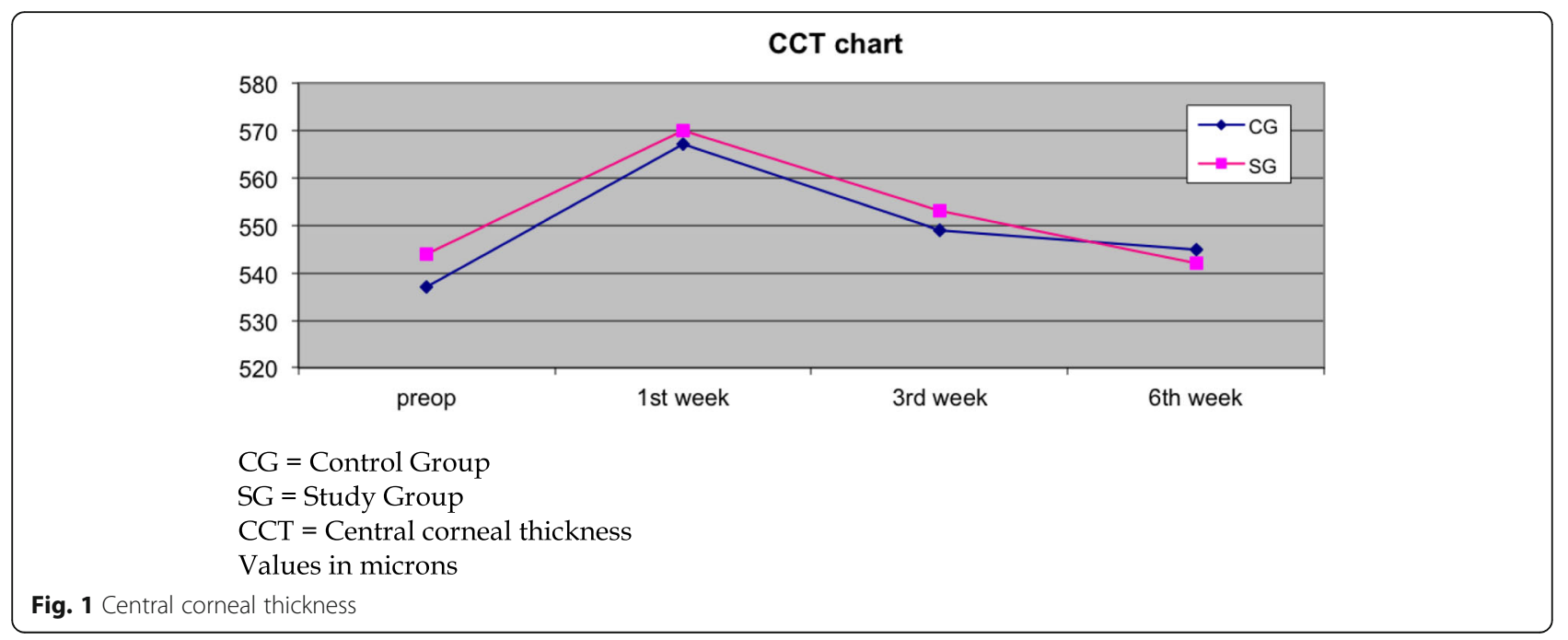




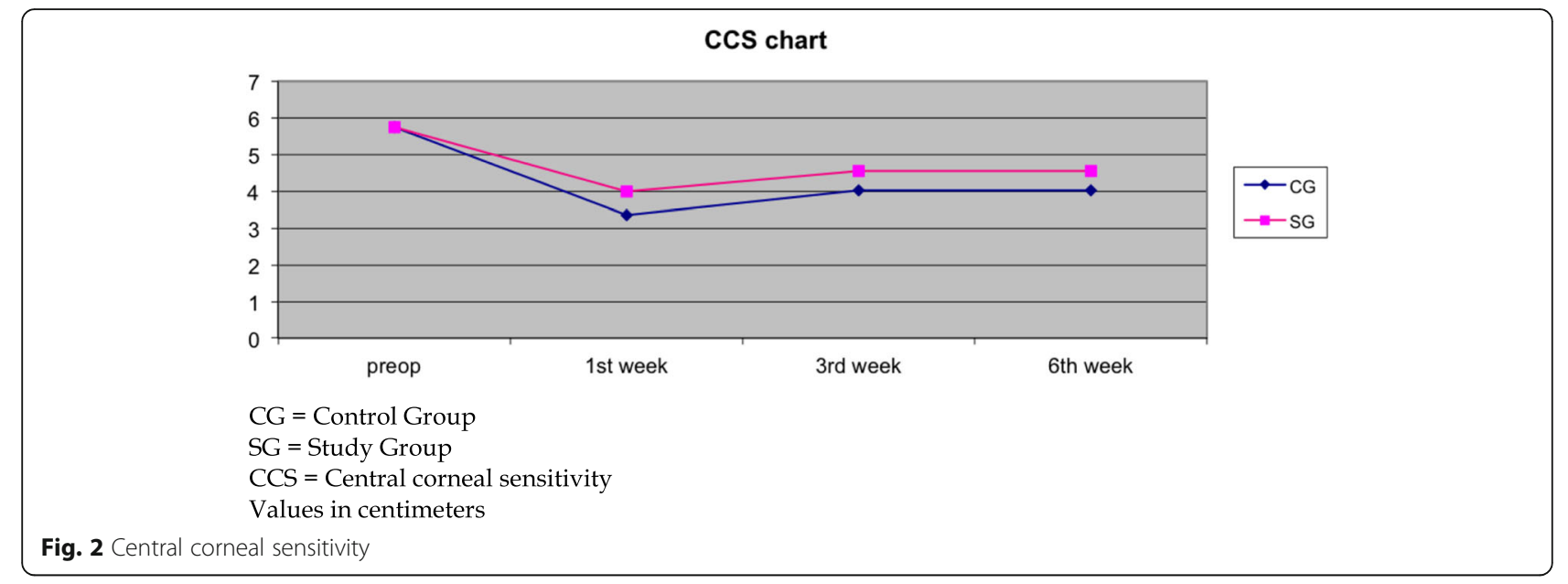

99\% of the cases since patients present impressive visual rehabilitation [10] and high levels of satisfaction [19]. The impressive visual capacity following cataract extraction surgery is not only associated with the removal of the opaque crystalline lens and its replacement with an artificial intraocular lens (IOL), but also due to the integrated properties and characteristics of the IOLs which attempt to address the majority of pre-existing refractive errors and aberrations. It is no surprise that modern cataract-extraction surgery has become part of refractive surgery [20].

Within this context, corneal surface and tear-film have become of major importance to cataract surgeons as it was traditionally for refractive surgeons. However, published experience suggests that the majority of post-cataract patients experience DED-like symptoms that vary in severity and duration [11, 21-25]. Among them are foreign body sensation, burning, stinging sensation, itchiness, tearing, blinking discomfort and pain. Our previous report presented the validation process of a novel surface discomfort index (SDI), which quantified, in a scale from 1 to 10 (best), the overall subjective discomfort feeling that post-cataract patients experience. SDI was constructed by four of the most commonlyexperienced symptoms which acted as components to the parameter (foreign body sensation, blinking discomfort, stinging sensation, and tearing sensation). Moreover, our previous report confirmed former studies and suggested that an artificial tear preparation should be added to the postoperative regime since it alleviates DED-like symptomatology. In fact, $0.1 \%$ sodium hyaluronate was found to be equally efficient in alleviating post-cataract DED as the more advanced polyethylene glycol 400/propylene glycol/ hydroxypropyl-guar; patients who received aforementioned medications presented significantly less

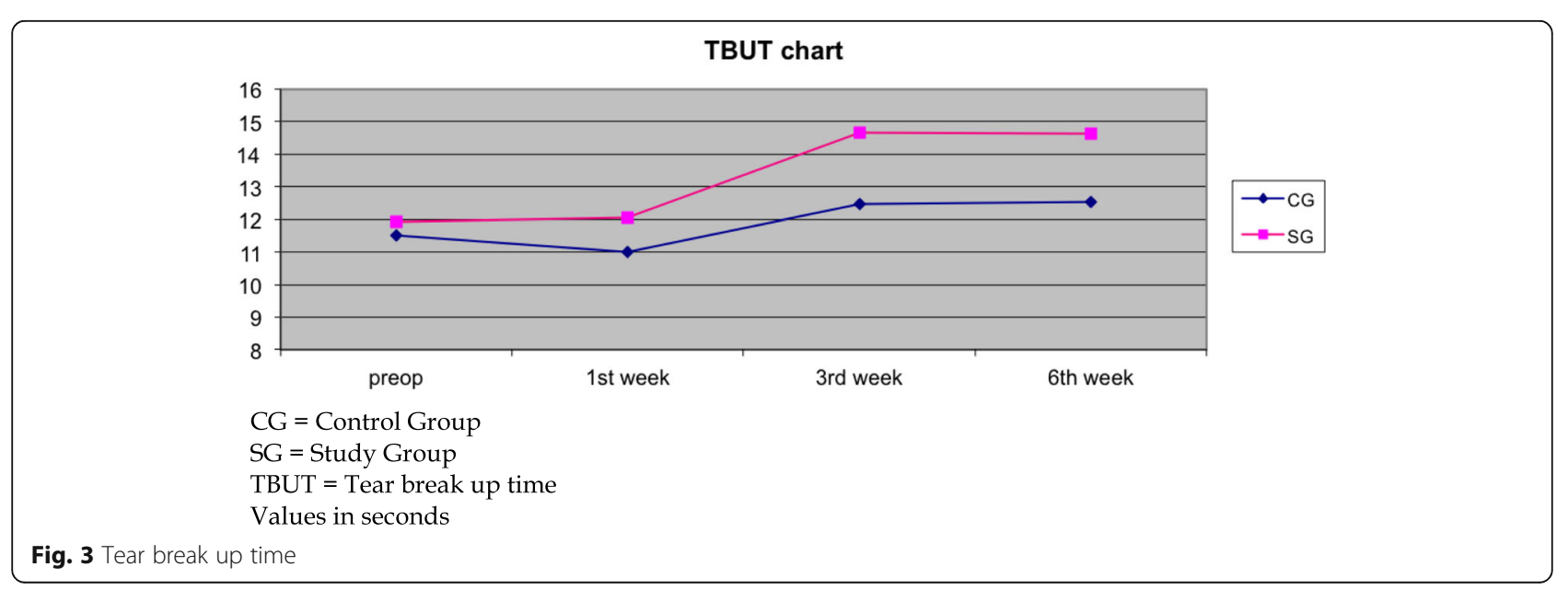




\section{Schirmer test chart}

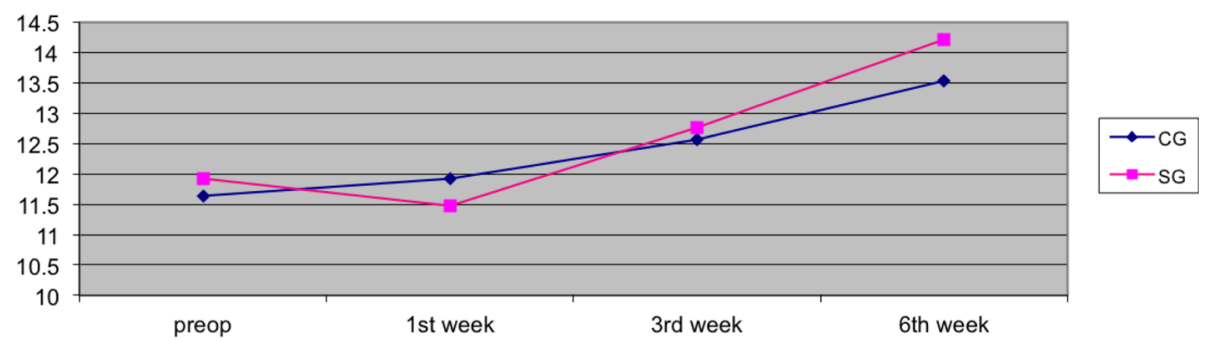

$\mathrm{CG}=$ Control Group

$\mathrm{SG}=$ Study Group

Values in millimeters

Fig. 4 Schirmer's chart

postoperative discomfort than those who received no artificial tears [15].

On the other hand, recent artificial tears preparations doubled the concentration of sodium hyaluronate to $0.2 \%$. However, no comparative clinical trials have been published to confirm a potential additional beneficial impact on DED due to the increased sodium hyaluronate concentration over the standard $0.1 \%$ one. Exploring the potential superiority of $0.2 \%$ sodium hyaluronate over $0.1 \%$ in patients who underwent phacoemulsification surgery was the primary objective of our study.

Regarding sodium hyaluronate, we do know that its viscoelastic properties facilitate the prolonged adhesion of the tear film layer [26]. Moreover, it has excellent moisturization properties and increases the total thickness of the lacrimal film [27]. On the other hand, it also mimics the rheological properties of the aqueous tear layer resulting in its stabilization $[28,29]$. In vitro reports demonstrated its antioxidant properties, which minimize the oxidative stress due to the intraoperative procedure and due to the preservatives and active ingredients of the standard postoperative medication [30]. In fact, sodium hyaluronate stimulates ocular surface tissue healing by humidifying the surface of the eye and restores the integrity of the corneal and conjunctival epithelium [31]. Recent reports indicated that sodium hyaluronate is equally efficient to $0.05 \%$ cyclosporine in patients with dry eye disease [32].

Although no comparative clinical trials have been published regarding the potential superiority of $0.2 \%$ sodium hyaluronate over $0.1 \%$ in patients who underwent phacoemulsification surgery, published literature has examined the impact of 0.2 and $0.18 \%$ sodium hyaluronate in patients with moderate to severe dry eye with keratitis or keratoconjunctivitis. Nonsuperiority of $0.2 \%$ over $0.1 \%$ sodium hyaluronate was demonstrated for the reduction of ocular surface lesions. However, some parameters, such as staining score and adverse effects,

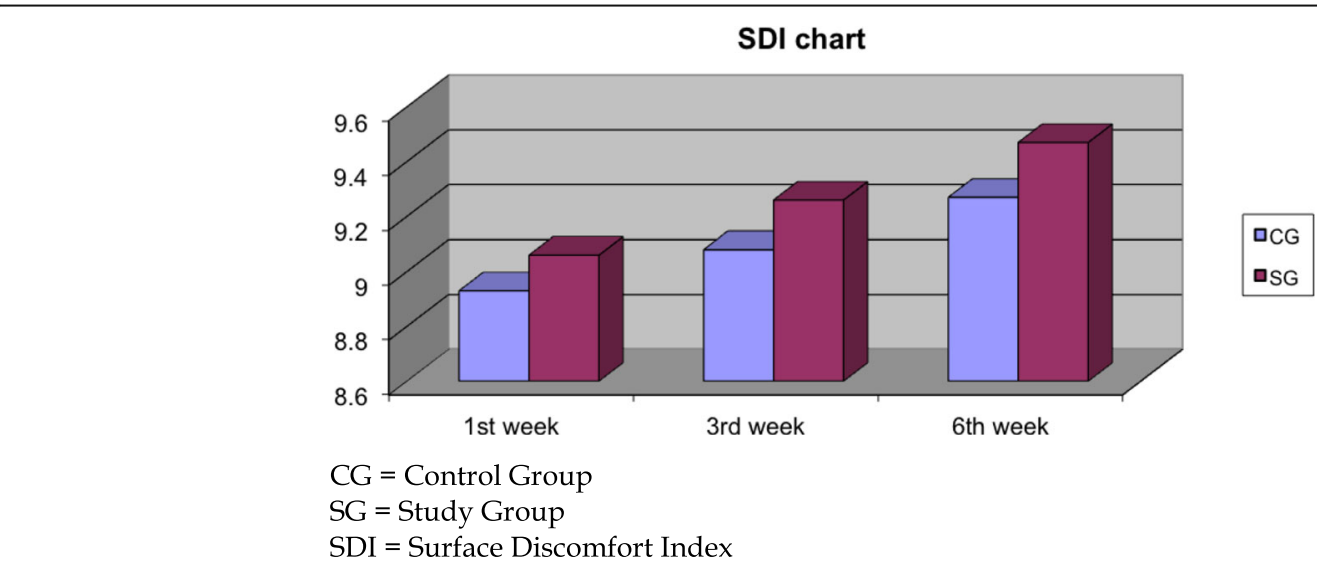

Fig. 5 Surface discomfort index 


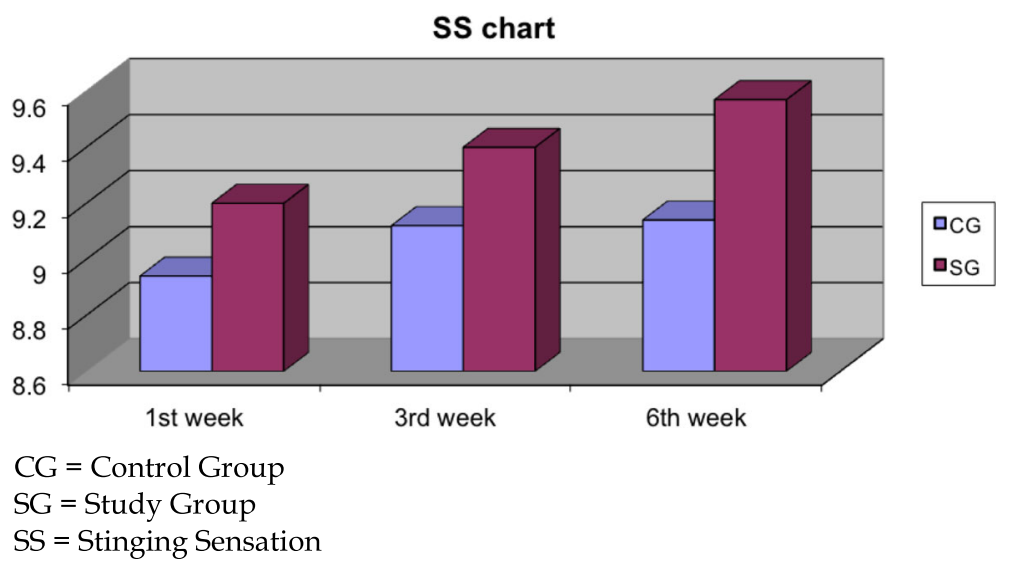

Fig. 6 Stinging sensation

presented better scores in $0.2 \%$ sodium hyaluronate concentrations [33, 34]. Of note, even higher concentrations of sodium hyaluronate $(0.3 \%)$ was found to perform better in laboratory and clinical settings $[35,36]$.

Our study outcomes indicated a potential overall superiority of the $0.2 \%$ concentration over the $0.1 \%$ in the majority of studied parameters: a) SG participants regained their preoperative CCT values at the last examination point, b) although both groups demonstrated significant reduced CCS values at all examination points, patients that received $0.2 \%$ sodium hyaluronate had significant better CCS, c) TBUT was significantly better in SG participants than in CG ones at the 3rd and 6th postoperative weeks. Last but not least, the overall surface discomfort that phacoemulsification patients experience was significantly less in $0.2 \%$ sodium hyaluronate patients at the 3rd and 6th weeks following their operation.
It seems that the increased concentration of sodium hyaluronate has an additional beneficial impact on the stinging sensation and the foreign body sensation, since these were the parameters of SDI that were significantly improved in study group patients.

\section{Conclusion}

A robust feature of our study is the number of participants that populated the study and control groups and the multi-centered design. Among the potential weaknesses is the limited number of parameters that were evaluated (i.e., corneal staining was not evaluated). Nevertheless, our study outcomes suggest that $0.2 \%$ sodium hyaluronate artificial tears medication is superior to the $0.1 \%$ formulation in patients that underwent cataract extraction surgery, and it should be considered as an important component of the postoperative regime.

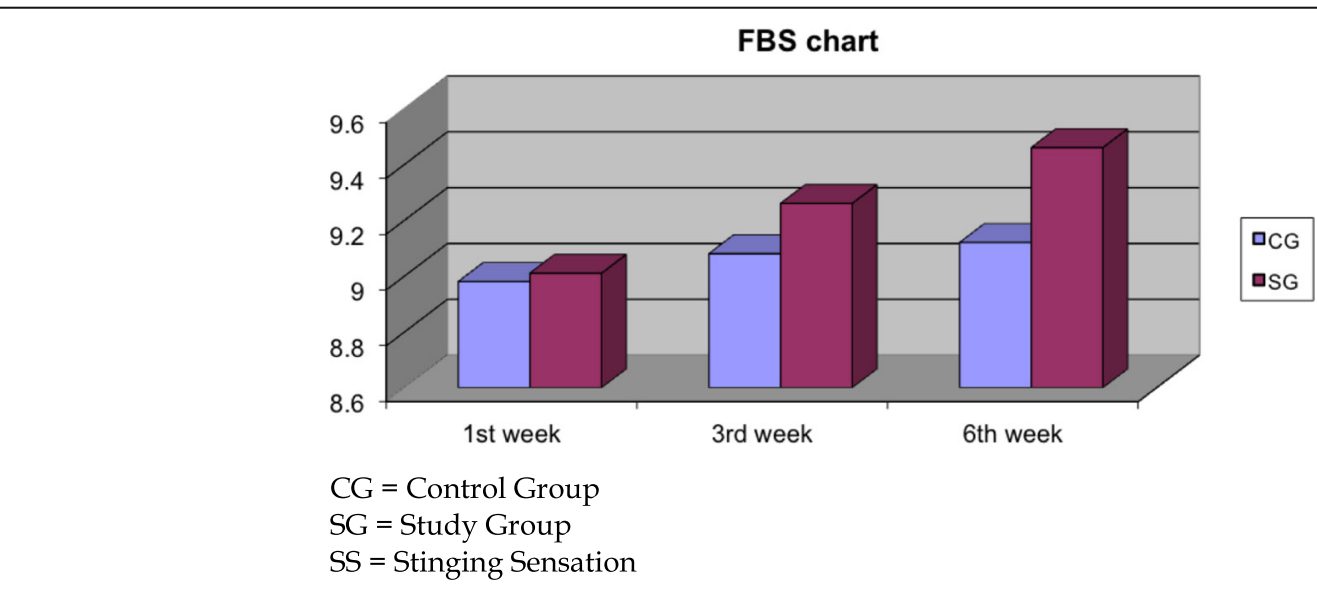

Fig. 7 Foreign body sensation 


\section{Acknowledgements}

None.

\section{Ethical approval and consent to participate}

This research followed the tenets of the Declaration of Helsinki. Approval was obtained by the Ethics committee of the University Hospital of Alexandroupolis. All participants provided written informed consent.

\section{Funding}

None.

No financial support was received for this study. None of the authors has any proprietary interests or conflicts of interest related to this submission. This manuscript is not simultaneously being considered for publication at any other journal.

\section{Availability of data and materials}

De-identified data are available in print form for one year following the conclusion of the study.

\section{Authors' contributions}

PN collected data and wrote the manuscript. EKP collected data and assisted in manuscript writing, GK collected data, NB collected data, ST performed all statistical analysis. GL designed the study, supervised the study, and critically revised the manuscript. All authors read and approved the final manuscript.

\section{Competing interests}

The authors declare that they have no competing interests.

\section{Author details}

'Department of Ophthalmology, University Hospital of Alexandroupolis, 68100 Dragana, Alexandroupolis, Greece. ${ }^{2}$ Department of Ophthalmology, Papanikolaou General Hospital, Thessaloniki, Greece. ${ }^{3}$ Department of Ophthalmology, Naval Hospital of Athens, Athens, Greece. ${ }^{4}$ Department of Ophthalmology, Athinaiki Kliniki, Athens, Greece.

\section{Received: 21 October 2018 Accepted: 27 January 2019}

\section{Published online: 11 February 2019}

\section{References}

1. Pascolini D, Mariotti SP. Global estimates of visual impairment: 2010. Br J Ophthalmol. 2012;96(5):614-8.

2. National Eye Institute - NEI - (2009). Facts about cataract. https://www.nei nih.gov/health/cataract/cataract_facts. Accessed 13 Oct 2018

3. Cataract, Priority eye diseases, Prevention of Blindness and Visual Impairment, WHO http://www.who.int/blindness/causes/priority/en/index1 html. Accessed 13 Oct 2018.

4. Bobrow JC, Beardsley TL, Jick SL, Rosenberg LF, Wiggins MN, Reich J, et al. Surgery for cataract. In: Bobrow JC, editors. 2014-2015 basic and clinical science course (BCSC): section 11: Lens and cataract. San Francisco, California: American Academy of Ophthalmology; 2014. p. 89-142.

5. Day AC, Gore DM, Bunce C, Evans JR. Laser-assisted cataract surgery versus standard ultrasound phacoemulsification cataract surgery. Cochrane Database Syst Rev. 2016;7:CD010735. https://doi.org/10.1002/14651858. CD010735.pub2

6. Kim SJ, Schoenberger SD, Thorne JE, Ehlers JP, Yeh S, Bakri SJ. Topical nonsteroidal anti-inflammatory drugs and cataract surgery: a report by the American Academy of Ophthalmology. Ophthalmology. 2015; 122(11):2159-68.

7. Behndig A, Cochener B, Güell JL, Kodjikian L, Mencucci R, Nuijts RM, et al. Endophthalmitis prophylaxis in cataract surgery: overview of current practice patterns in 9 European countries. J Cataract Refract Surg. 2013; 39(9):1421-31.

8. Sutu C, Fukuoka H, Afshari NA. Mechanisms and management of dry eye in cataract surgery patients. Curr Opin Ophthalmol. 2016;27(1):24-30.

9. Kasetsuwan N, Satitpitakul V, Changul T, Jariyakosol S. Incidence and pattern of dry eye after cataract surgery. PLoS One. 2013:8(11):e78657.

10. Hood CT, Sugar A. Subjective complaints after cataract surgery: common causes and management strategies. Curr Opin Ophthalmol. 2015;26(1):45-9.
11. Li XM, Hu L, Hu J, Wang W. Investigation of dry eye disease and analysis of the pathogenic factors in patients after cataract surgery. Cornea. 2007;26(9 suppl 1):S16-20.

12. Hardten DR. Dry eye disease in patients after cataract surgery. Cornea. 2008; 27(7):855.

13. Sitompul R, Sancoyo GS, Hutauruk JA, Gondhowiardjo TD. Sensitivity change in cornea and tear layer due to incision difference on cataract surgery with either manual small-incision cataract surgery or phacoemulsification. Cornea. 2008;27 Suppl 1:S13-8.

14. Jiang D, Xiao X, Fu T, Mashaghi A, Liu Q, Hong J. Transient tear film dysfunction after cataract surgery in diabetic patients. PLoS One. 2016;11(1): e0146752. https://doi.org/10.1371/journal.pone.0146752.

15. Labiris G, Ntonti $P$, Sideroudi H, Kozobolis V. Impact of polyethylene glycol 400/propylene glycol/hydroxypropyl-guar and $0.1 \%$ sodium hyaluronate on postoperative discomfort following cataract extraction surgery: a comparative study. Eye Vis (Lond). 2017:4:13

16. Mencucci R, Boccalini C, Caputo R, Favuzza E. Effect of a hyaluronic acid and carboxymethylcellulose ophthalmic solution on ocular comfort and tear-film instability after cataract surgery. J Cataract Refract Surg. 2015; 41 (8):1699-704.

17. Liu Y, Zeng M, Liu X, Luo L, Yuan Z, Xia Y, et al. Torsional mode versus conventional ultrasound mode phacoemulsification: randomized comparative clinical study. J Cataract Refract Surg. 2007;33:287-92.

18. Williams A, Sloan FA, Lee PP. Longitudinal rates of cataract surgery. Arch Ophthalmol. 2006;124:1308-14.

19. Brown GC, Brown MM, Menezes A, Busbee BG, Lieske HB, Lieske PA Cataract surgery cost utility revisited in 2012: a new economic paradigm. Ophthalmology. 2013;120:2367-76.

20. Buratto L, Brint SF, Bocuzzi D. Accommodative intraocular lenses. In: Buratto $L$, Brint SF, Bocuzzi D, editors. Cataract surgery and intraocular lenses. Thorofare, New Jersey: SLACK Incorporated; 2014. p. 73-8.

21. Silverstein SM, Cable MG, Sadri E, Peace JH, Fong R, Chandler SP, et al. Once daily dosing of bromfenac ophthalmic solution $0.09 \%$ for postoperative ocular inflammation and pain. Curr Med Res Opin. 2011:27(9):1693-703.

22. Maxwell WA, Reiser HJ, Stewart RH, Cavanagh HD, Walters TR, Sager DP, et al. Nepafenac dosing frequency for ocular pain and inflammation associated with cataract surgery. J Ocul Pharmacol Ther. 2008;24(6):593-9.

23. Camesasca Fl, Bianchi C, Beltrame G, Caporossi A, Piovella M, Rapisarda A, et al. Control of inflammation and prophylaxis of endophthalmitis after cataract surgery: a multicenter study. Eur J Ophthalmol. 2007:17(1):733-42.

24. Fong R, Leitritz M, Siou-Mermet R, Erb T. Loteprednol etabonate gel 0.5\% for postoperative pain and inflammation after cataract surgery: results of a multicenter trial. Clin Ophthalmol. 2012:6:1113-24.

25. Chen $X$, Yuan $R$, Sun $M$, Chen $X$, Lin $S$, Ye J, et al. Efficacy of an ocular bandage contact lens for the treatment of dry eye after phacoemulsification. BMC Ophthalmol. 2019;19(1):13.

26. Abelson MB, Lafond A. 3,500 years of artificial tears. Rev Ophthalmol. 2014; 14(12):44-7

27. Kaya S, Schmidl D, Schmetterer L, Witkowska KJ, Unterhuber A, Aranha Dos Santos $V$, et al. Effect of hyaluronic acid on tear film thickness as assessed with ultra-high resolution optical coherence tomography. Acta Ophthalmol. 2015;93(5):439-43.

28. Guillon M, Maissa C, Ho S. Evaluation of the effects on conjunctival tissues of Optive eyedrops over one month usage. Cont Lens Anterior Eye. 2010; 33(2):93-9.

29. Dreyfuss JL, Regatieri CV, Coelho B, Barbosa JB, De Freitas D, Nader HB, et al Altered hyaluronic acid content in tear fluid of patients with adenoviral conjunctivitis. An Acad Bras Cienc. 2015;87(1):455-62.

30. Debbasch C, De La Salle SB, Brignole F, Rat P, Warnet JM, Baudouin C. Cytoprotective effects of hyaluronic acid and Carbomer 934P in ocular surface epithelial cells. Invest Ophthalmol Vis Sci. 2002:43(11):3409-15.

31. Ho WT, Chiang TH, Chang SW, Chen YH, Hu FR, Wang IJ. Enhanced corneal wound healing with hyaluronic acid and high-potassium artificial tears. Clin Exp Optom. 2013:96(6):536-41.

32. Park Y, Song JS, Choi CY, Yoon KC, Lee HK, Kim HS. A randomized multicenter study comparing $0.1,0.15$, and $0.3 \%$ sodium hyaluronate with 0 . 05\% cyclosporine in the treatment of dry eye. J Ocul Pharmacol Ther. 2017; 33(2):66-72.

33. Groß D, Childs M, Piaton JM. Comparison of 0.2 and $0.18 \%$ hyaluronate eye drops in patients with moderate to severe dry eye with keratitis or keratoconjunctivitis. Clin Ophthalmol. 2017;11:631-8. 
34. Carlson E, Kao WWY, Ogundele A. Impact of hyaluronic acid-containing artificial tear products on reepithelialization in an in vivo corneal wound model. J Ocul Pharmacol Ther. 2018;34(4):360-4.

35. Johnson ME, Murphy PJ, Boulton M. Effectiveness of sodium hyaluronate eyedrops in the treatment of dry eye. Graefes Arch Clin Exp Ophthalmol. 2006;244(1):109-12.

36. You IC, Li Y, Jin R, Ahn M, Choi W, Yoon KC. Comparison of 0.1, 0.18, and 0 . $3 \%$ hyaluronic acid eye drops in the treatment of experimental dry eye. J Ocul Pharmacol Ther. 2018;34(8):557-64.

Ready to submit your research? Choose BMC and benefit from:

- fast, convenient online submission

- thorough peer review by experienced researchers in your field

- rapid publication on acceptance

- support for research data, including large and complex data types

- gold Open Access which fosters wider collaboration and increased citations

- maximum visibility for your research: over $100 \mathrm{M}$ website views per year

At BMC, research is always in progress.

Learn more biomedcentral.com/submissions 